\title{
The evolution of sports medicine in Singapore
}

Benedict $\underline{\operatorname{Tan}}^{1}$, MBBs, MSpMed

ABSTRACT Sports medicine is a relatively new subspecialty in Singapore. This commentary chronicles its evolution in Singapore from 1969, through various milestones, to the present day. The first sports medicine clinic in Singapore was established in 1971 at Farrer Park. Notable institutions that followed include the Sports Medicine and Research Centre (1973), Soldier Performance Centre, Changi Sports Medicine Centre (2003), Singapore Sports Medicine Centre (2006), and other multidisciplinary centres of restructured hospitals. Formal groundwork to establish sports medicine as a subspecialty began in 2005 , with its first trainee commencing traineeship at the Changi Sports Medicine Centre in 2007, and culminated in the subspecialty register at the beginning of 2011. Also captured in this discussion are the broader scopes of sports medicine, including military sports medicine, the sports sciences, exercise medicine, and event medical coverage.

Keywords: exercise medicine, history, physical activity, sports science, subspecialty

\section{CURRENT LANDSCAPE}

In Europe, North America, Australia and New Zealand, sports medicine is well established and a standard offering in both the public and private sectors. In recent years, the Singaporean public has also grown accustomed to sports medicine services. We see sports medicine clinics and centres in the private space, the biggest and most comprehensive being the 5,000-sq ft Singapore Sports Medicine Centre (SSMC), situated in the Novena medical hub.

In restructured hospitals, sports medicine first appeared when Changi Sports Medicine Centre (CSMC) was established in Changi General Hospital in 2003. Now, Khoo Teck Puat Hospital, Tan Tock Seng Hospital, National University Hospital and Jurong General Hospital also boast the presence of a team of sports physicians.

Sports medicine centres in restructured hospitals tend to be quite large and comprehensive. CSMC, for example, occupies well over 12,000 sq ft and comes complete with a full gymnasium and outdoor track. It has a sports cardiologist, endocrinologist, bariatric surgeon, and a team of sports orthopaedic surgeons attending to patients under the same roof as 11 full-time sports medicine practitioners (from medical officers to senior consultants). Also under that same roof are sports physiotherapists, clinical sports trainers, sports massage therapists, sports dietitians and sports podiatrists. CSMC has developed a sports nursing track, and SSMC even has its own sports psychologists. This multidisciplinary nature is characteristic of sports medicine practices.

\section{THE BEGINNINGS}

It was not that long ago that the term 'sports medicine' was unfamiliar to the Singaporean public. Even doctors were confused between sports medicine and orthopaedic surgery, and the public often thought that sports physicians were physiotherapists.

The birth of sports medicine in Singapore can be traced back to 1969, when the Ministry of Health $(\mathrm{MOH})$ sent Dr Lindy Lin to the United States on a World Health Organization scholarship.(1) Returning in 1971, Dr Lin was seconded to the National Sports Promotion Board (a statutory board under the then Ministry of Social Affairs) to start a humble unit at Farrer Park. The unit had only three staff - Dr Lin, physiotherapist Ann Choo and nurse Cynthia Low. The following year, the Minister for Social Affairs, Mr Othman Wok, remarked, "I would like to see, with the completion of the National Stadium Complex, that we become a centre for sports medicine." The National Stadium was completed in time for the 1973 Southeast Asia Peninsula Games. Under its stands, the 10,000-sq ft Runme Shaw Centre for Sports Medicine and Research was inaugurated on August 31, 1973. Its name was later shortened to Sports Medicine and Research Centre (SMRC).

SMRC grew steadily under the headship of sports medicine pioneers such as the West German-trained Dr Giam Choo Keong (1973-1991) and the United States-trained Dr Teh Kong Chuan (1991-2008). SMRC saw to the needs of our national and school athletes, both in terms of injury management as well as performance enhancement.

\section{MILITARY SPORTS MEDICINE}

In the meantime, another seed for sports medicine was planted by the Singapore Armed Forces (SAF). ${ }^{(2)}$ In the early 1980s, SAF established the Physical Performance Laboratory. This quickly grew into the Soldier Performance Centre (SPC), which offers musculoskeletal injury management, physiotherapy and injury prevention initiatives for our servicemen. SAF has full-time sports physicians within its ranks, and continues to

${ }^{1}$ Department of Sports Medicine, Changi General Hospital, Singapore

Correspondence: Dr Benedict Tan, Chief, Department of Sports Medicine, Changi General Hospital, 2 Simei Street 3, Singapore 529889. benedict_tan@cgh.com.sg 
invest in enhancing its in-house sports medicine capabilities. In November 2011, SAF Medical Corps signed a Memorandum of Understanding with Changi General Hospital for CSMC to provide systematic sports medicine training for successive cohorts of National Service medical officers, and subspecialty training for selected SAF regular officers.

The SAF was also where two branches of sports medicine (underwater medicine and aviation medicine) developed in Singapore. The Navy took the lead in developing underwater medicine (comprising diving, hyperbaric and submarine medicine). The Naval Underwater Medicine Centre served not only naval divers, but also commercial and recreational divers. When Singapore first started tunneling works for the Mass Rapid Transit system in 1983, it was the Navy that provided the hyperbaric medicine support for the workers (tunneling was done in a hyperbaric environment to keep water out). The first commercial hospital-based hyperbaric medicine facility was established at Tan Tock Seng Hospital in the early 2000s. In 2008, the Republic of Singapore Navy and Singapore General Hospital (SGH) jointly set up the SGH Hyperbaric and Diving Medicine Centre to provide a one-stop facility for civilian and military divers. A parallel development, centred around the Republic of Singapore Air Force Aeromedical Centre, took place for aviation medicine.

\section{SPORTS SCIENCES}

Sports medicine encompasses the sports sciences, which includes exercise physiology, sports biomechanics, strength and conditioning, sports nutrition and sports psychology. Sports physicians need to be adept at the sports sciences. Both SMRC and SPC, and later, the Defence Medical and Environmental Research Institute, were active in the sports sciences.

Much of the research done at these institutions, such as those on heat injuries and exercise-associated hyponatraemia, have clinical implications. ${ }^{(3)}$ Other research focused on performance enhancement. SMRC's sports physicians worked with sports scientists to build the world's first hiking dynamometer (an apparatus that quantifies the work done by sailors while hiking out on a boat). ${ }^{(4)}$ Much original research was also done on enhancing performance in indigenous Asian sports such as sepak takraw and pencak silat. ${ }^{(5)}$

\section{ENTERING THE MAINSTREAM}

Prior to 2003, the two foci of sports medicine were SMRC and SPC, under the Singapore Sports Council (a statutory board under the then Ministry of Community Development, Youth and Sports) and SAF (under the Ministry of Defence), respectively. Although sports medicine is a medical discipline, neither SMRC nor SPC was directly under $\mathrm{MOH}$ - sports medicine had limited access to $\mathrm{MOH}^{\prime}$ s healthcare framework and resources such as the Health Manpower Development Programme.

In 2003, I was asked to join Changi General Hospital to start up CSMC. With CSMC sited within a restructured hospital, sports medicine came directly under $\mathrm{MOH}^{\prime} \mathrm{s}$ supervisory framework and soon emerged as a mainstream discipline, integrating with the other medical disciplines. There was a rapid levelling up of sports medicine practice (e.g. clinical research, postgraduate training and continuing education, attention to integrated care and medical innovation) to be on par with the other medical disciplines.

\section{SPORTS MEDICINE AS A SUBSPECIALTY}

On July 14, 2005, I was tasked to chair a workgroup appointed by the Joint Committee on Specialist Training to establish sports medicine as a subspecialty in Singapore. The Specialist Accreditation Board ratified sports medicine as a subspecialty in late 2006. In November 2007, CSMC became the first institution to be accredited for sports medicine training and took in Singapore's first sports medicine trainee. Prior to that, all sports medicine practitioners had to do their postgraduate training overseas, mostly in Australia or the United States. Singapore's subspecialty register was finally established at the start of 2011, and sports medicine was immediately listed on the register. There are currently 23 sports physicians listed on the subspecialty register.

To be eligible for sports medicine traineeship in Singapore, one needs to first exit from family medicine, emergency medicine, internal medicine or orthopaedic surgery. The intention of this varied background is to foster diversity. Sports medicine subspecialty training spans three years and includes rotations through institutional sports medicine, community sports medicine, sports science, and research postings. During this time, trainees pick up skills in sports injury management and prevention, preparticipation screening, event medical coverage, team physician duties, clinical exercise testing, exercise prescription, musculoskeletal ultrasonography and ultrasonography-guided procedures, extra corporeal shock wave therapy, kinetics and kinematics, anti-doping and sports science (performance enhancement).

\section{EXERCISE MEDICINE AND PROMOTION OF PHYSICAL ACTIVITY}

The term 'sports medicine' gives the impression that it serves only elite and competitive athletes. This is not the case. In the United Kingdom, it is common to use the term 'sports and exercise medicine'. In other parts of the world, such as in Singapore and Australia, where the more succinct term 'sports medicine' is commonly used, it is implied to encompass exercise medicine as well.

An integral part of sports medicine is the promotion of physical activity. With sedentarism or physical inactivity being the fourth biggest risk factor for global deaths, our sports physicians have undertaken the task of promoting physical activity in an attempt to reduce the chronic disease burden. ${ }^{(6)}$ SMRC developed standards for fitness assessment for the general public, leading to the National Aerobic Fitness Award 
scheme in 1976. (1) Singapore schools adopted this as the National Physical Fitness Award in 1982. Another innovation by SMRC is the 1999 Self-Test Estimate of Physical Fitness programme, which uses a timed ascent up a 12-storey HDB (Housing and Development Board) apartment block, both as a form of training and as a fitness test. ${ }^{(7)}$ Not forgetting the young, SMRC also evaluated a popular arcade game, Dance Dance Revolution, for the purpose of aerobic training and weight loss. ${ }^{(8)}$ In 2003, CSMC partnered the industry to launch the nationwide Step With It, Singapore!, where pedometers were used to promote physical activity in schools and workplaces.

A major effort by the sports medicine community to encourage active living in Singaporeans, especially those with chronic noncommunicable diseases, was launched in July 2011. Hosted by CSMC, with support from the American College of Sports Medicine, the Exercise is Medicine Singapore Task Force was established to train healthcare providers and fitness professionals to be confident in their prescription of exercise and supervision of patients, among other related objectives. The Exercise is Medicine Southeast Asia Regional Centre is also situated in Singapore.

\section{EVENT MEDICAL COVERAGE}

As Singapore started hosting sports events of greater scale and complexity, the medical coverage of events also went beyond the bread-and-butter soccer matches and grew in sophistication. The 70,000-participant Standard Chartered Singapore Marathon tested our capacity, while the OSIM Triathlon and Aviva Half Ironman tested our capabilities on the water and cycling tracks. The chief medical officer of the Formula 1 Singapore Grand Prix is a Singaporean sports physician who is also responsible for training the medical teams of other Asian Grand Prix events. Fast-growing regional martial arts events such as the One Fighting Championship are fast-paced, medically high-risk events, and CSMC has developed specialised event medical coverage expertise to go with it.

\section{MEETING SINGAPORE'S FUTURE NEEDS}

The demand for sports medicine has risen exponentially. Starting with only one sports physician in 2003, CSMC now has 11 full-time sports medicine practitioners. Many factors point to a further increase in the demand for sports medicine - our elite athletes are competing at higher levels; sports participation rates are climbing, as evidenced by the rising number of mass events and increasing registrations at these events; Singapore will attract many more international sports events when the \$1.87 billion Sports Hub opens in 2014; Singaporeans have an increased appetite for extreme sports, adventure sports and ultramarathon events; and the chronic disease burden is increasing, thus raising the demand for exercise prescription and supervised exercise.

As CSMC celebrates its 10th anniversary this year, there is much to look forward to, from the opening of the Sports Hub in 2014 and the 2015 Southeast Asian Games on home ground, to the 2016 Olympics, and much more.

\section{REFERENCES}

1. Singapore Sports Council. Rising to the occasion: the coming of age of Sports Medicine \& Research Centre. Singapore: The Council, 2003.

2. Singapore Armed Forces Medical Corps. Ideas to Reality: The SAF Medical Corp 45th Anniversary. Singapore: Singapore Armed Forces Medical Corps, 2012.

3. Lee JK, Nio AQ, Ang WH, et al. First reported cases of exercise-associated hyponatremia in Asia. Int J Sports Med 2011; 32:297-302.

4. Tan B, Aziz AR, Spurway NC, et al. Indicators of maximal hiking performance in Laser sailors. Eur J Appl Physiol 2006; 98:169-76.

5. Aziz AR, Tan B, Teh KC. Physiological responses during matches and profile of elite pencak silat exponents. J Sports Sci Med 2002; 1:147-55.

6. World Health Organization. Global Health Risks: Mortality and burden of disease attributable to selected major risks. World Health Organization, 2004.

7. Teh KC, Aziz AR. Heart rate, oxygen uptake and the energy cost of ascending and descending the stairs. Med Sci Sports Exerc 2002; 34:695-9.

8. Tan B, Aziz AR, Chua K, Teh KC. Aerobic demands of the dance simulation game. Int J Sports Med 2002; 23:125-9. 